УДК 665:535.33/.34

А. В. ОРЕШЕНКОВ, доктор техн. наук

А. Н. ПРИВАЛЕНКО, канд. техн. наук, доцент

Г. М. БАЛАК, канд. хим. наук, стариий научный сотрудник

Федеральное автономное учреждение «25 ГосНИИ химмотологии Минобороны России»

Н. Н. ПУЛЯЕВ, канд. техн. наук, доцент

Федеральное государственное бюджетное образовательное учреждение высшего профессионального образования «Московский государственный агроинженерный университет имени В. П. Горячкина»

A. V. ORESHENKOV, $P h D$ (Eng)

A. N. PRIVALENKO, PhD (Eng), associate professor

G. M. BALAK, PhD (Chem), senior researcher

Federal Autonomous Establishment

"The 25th State Research Institute of Chemmotology of the Ministry of Defence"

N. N. PULYAEV, PhD (Eng), associate professor

Federal State Budgetary Establishment of Higher Professional Education

"Moscow State Agroengineering University named after V. P. Goryachkin"

\title{
СПЕКТРОСКОПИЧЕСКИЕ МЕТОДЫ В ХИММОТОЛОГИИ
}

\author{
SPECTROSCOPIC METHODS IN CHEMMOTOLOGY
}

Представлен краткий обзор теории и практики применения спектроскопических методов при проведении химмотологических исследований и оценке качества нефтепродуктов. Рассмотрены такие методы, как атомная, молекулярная, инфракрасная, ультрафиолетовая, атомно-абсорбционная, флуоресцентная спектроскопии и некоторые другие.

Ключевые слова: атомная спектроскопия, молекулярная оптическая спектроскопия, молекулярный спектр, количественный анализ нефтепродуктов, инфракрасная спектроскопия, ультрафиолетовая спектроскопия, атомно-абсорбиионная спектроскопия, флуоресцентная спектроскопия.

The article provides a brief overview of the theory and practice of spectroscopic methods in conducting chemmotology research and evaluation of the quality of oil products. It considers the methods such as atomic, molecular, infrared, ultraviolet, atomic absorption, fluorescence spectroscopy, and some other types.

Key words: atomic spectroscopy, molecular optical spectroscopy, molecular spectrum, quantitative analysis of petroleum products, infrared spectroscopy, ultraviolet spectroscopy, atomic absorption spectroscopy, fluorescence spectroscopy.

Спектральный анализ достиг своего совершенства в пределах известных законов физики и применяется в различных областях науки, производства, медицины. Методы спектроскопии нашли специальное применение и в химмотологии в качестве инструментальных, позволяющих исследовать химическое строение, структуру и взаимное влияние атомов в молекуле, и аналитических - при идентификации и контроле качества топлив, масел, смазок и специальных жидкостей (нефтепродуктов). Накопление данных, полученных различными спектроскопическими методами, позволяет выявлять закономерности, связывающие физико-химические свойства нефтепродуктов с химическим строением, оптимизировать состав и устанавливать корреляционные связи между различными показателями качества нефтепродуктов.

При определении физических характеристик химмотологических систем и исследовании протекающих в них процессов с помощью спектроскопических методов используется способность атомов и молекул поглощать, испускать или рассеивать электромагнитное излучение.

Атомный спектр получают путем измерения абсорбции излучения при определенной длине волны в зависимости от 
концентрации химического элемента в нефтепродукте, что исключает необходимость измерения всего спектра поглощения. Обычно зависимость оптической плотности (абсорбционности) от содержания элемента выражают в виде градуировочного графика, построенного по растворам сравнения, где известно содержание определяемого элемента.

Получение молекулярного спектра требует измерения полного спектра поглощения в зависимости от длины волны (волнового числа) и идентификации полос поглощения. Количественный анализ нефтепродукта по молекулярным спектрам основан на законе Бугера-Ламберта-Бера и включает определение аналитической длины волны (соответствует максимуму светопоглощения) и соответствующей ей абсорбционности нескольких образцов сравнения (стандартных образцов).

Спектры испускания атомов и молекул нефтепродуктов в инфракрасной, видимой и ультрафиолетовой областях измеряют по единой схеме, различия заключаются в используемой аппаратуре и методе анализа (эмиссионный, флуоресцентный). Спектр получают путем передачи дополнительной энергии (возбуждения) частицам вещества. Количественный анализ с использованием этих спектров также требует построения калибровочных графиков с использованием образцов сравнения.

В химмотологии для получения оптических спектров поглощения и испускания широко используются методы инфракрасной, ультрафиолетовой и атомноабсорбционной спектроскопии.

Область полос поглощения в инфракрасной спектроскопии находится в диапазоне 4000...400 см-1 и включает основные колебания групп органических соединений (рис. 1) [1, 2].

На рис. 1 показаны участки поглощения для различных типов основных колебаний, включающих элементы C, H, N и O. Поглощение в диапазоне волновых чисел 3700...1500 см-1, обусловленное валентными колебаниями связей $\mathrm{X}-\mathrm{H}, \mathrm{X}=\mathrm{Y}$ и $\mathrm{X} \equiv \mathrm{Y}$, легко выделяется в спектре и является областью функциональных групп. Область поглощения ниже 1500 см$^{-1}$ (область «отпечатков пальцев») в основном используется для идентификации веществ, хотя сложнее в интерпретации, чем основная область.

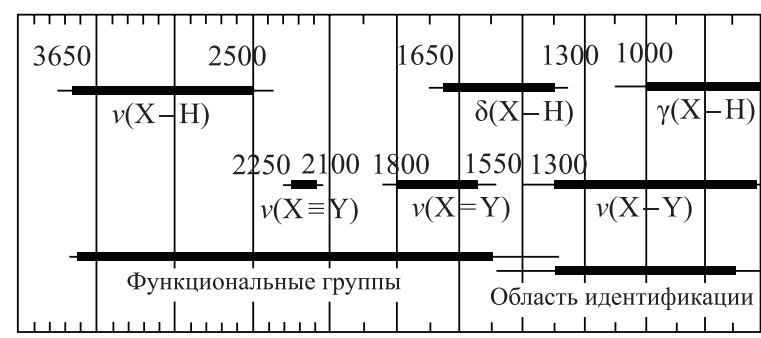

4000350030002500200018001600140012001000800

Рис. 1. Область основных колебаний в инфракрасном спектре:

$v, \delta, \gamma$ - колебания валентные, деформационные (плоскостные и внеплоскостные) соответственно;

X, Y - углерод, азот (кислород) соответственно;

H - водород; - - участки поглощения наиболее значимых колебаний;

- - участки редко встречающихся колебаний

Не все полосы в основной области обусловлены возбуждением чистых валентных или деформационных колебаний. Ряд полос обусловлен колебательным взаимодействием между валентными и деформационными колебаниями с близкими начальными частотами, приводящим к их «смешиванию». Получающееся в результате взаимодействия нормальное колебание содержит в себе оба типа колебаний.

Инфракрасная спектроскопия является достаточно информативным инструментом изучения свойств нефтепродуктов, исследования их структурно-группового состава по колебательным спектрам и механизма действия присадок, а также контроля качества нефтепродуктов. Например, контроль наличия и содержания моющих присадок в автомобильных бензинах, позволяющих уменьшить количество отложений в топливной системе и снизить уровень токсичности отработавших газов. Экспериментально установлено, что содержание таких присадок в бензине должно находиться в пределах от 0,01 до 0,04 \%. Передозировка присадок приводит к интенсификации процесса образования отложений в топливной системе двигателя.

Результаты поиска методов, позволяющих контролировать содержание присадок в бензине, свидетельствуют об эффективности спектроскопических методов. Так, авторами [3] показана принципиальная возможность определения моющих 
присадок в бензинах с помощью инфракрасной спектроскопии в областях полос поглощения 1051...1192 см$^{-1}$, характерной для валентных колебаний связи $\mathrm{Ph}-\mathrm{O}$ присадок на основе высокомолекулярного основания Маниха («Keropur 3619», «Keropur 3458N», «НiТес 6430»), и 1150...1250 см-1, 1400..1500 $\mathrm{cm}^{-1}, 1700$ см$^{-1}$ и $2900 \ldots 3050$ см$^{-1}$ для присадок «Каскад-9» и «Каскад-9 ТОС». При этом относительная погрешность измерения содержания присадок в бензине в диапазоне 200...600 мг/дм ${ }^{3}$ составила $20 \%$ при доверительной вероятности 0,95.

В работе [4] для ряда физикохимических свойств нефтепродуктов был установлен строго определенный набор характеристических полос поглощения и разработана методика идентификации и оценки кондиционности топлив по данным инфракрасной спектроскопии, явившаяся основой создания базы данных и автоматизированной системы контроля качества горючего с использованием инфракрасных спектров. В табл. 1 в качестве примера представлены корреляционные зависимости характеристических полос поглощения (ХПП) от значений показателей качества дизельного топлива Л-0,2-62.
Группа методов электронной ультрафиолетовой спектроскопии охватывает оптические спектры в диапазоне, связанные с переходами между различными электронными состояниями атомов и молекул, не только в ультрафиолетовой (5...400 нм), но и в видимой (400...750 нм), и в ближней инфракрасной областях $(750 \ldots 1200$ нм). Электронные спектры многоатомных молекул исследуются обычно как спектры поглощения, возникающие в результате переходов из основного электронного состояния в возбужденное за счет поглощения квантов электромагнитного излучения из сплошного спектра источника, или люминесценции - в результате перехода молекулы из возбужденного состояния в основное с испусканием электромагнитного излучения, дающего линейчатый спектр. Методы электронной спектроскопии являются основными экспериментальными методами теоретической и квантовой химии, позволяющими производить прецизионные измерения молекулярных постоянных по электронно-колебательно-вращательным спектрам только для двухатомных и некоторых простейших многоатомных молекул в газовой фазе.

Таблица 1

Корреляционные зависимости характеристических полос поглощения от значений показателей качества дизельного топлива Л-0,2-62

\begin{tabular}{|c|c|c|c|c|c|}
\hline \multirow[b]{2}{*}{ ХПП, $\mathrm{cm}^{-1}$} & \multicolumn{5}{|c|}{ Коэффициент корреляции для показателей } \\
\hline & плотность & $\begin{array}{c}50 \text { \% фракция } \\
\text { выкипания }\end{array}$ & кислотность & $\begin{array}{l}\text { температура } \\
\text { помутнения }\end{array}$ & $\begin{array}{c}\text { температура } \\
\text { застывания }\end{array}$ \\
\hline 848 & 0,83 & - & $-0,75$ & - & - \\
\hline 811 & 0,81 & - & $-0,81$ & 0,74 & 0,81 \\
\hline 832 & 0,81 & 0,75 & $-0,77$ & - & 0,76 \\
\hline 474 & 0,74 & - & - & - & - \\
\hline 722 & - & 0,91 & 0,79 & 0,78 & 0,84 \\
\hline 1306 & - & 0,83 & - & - & - \\
\hline 1606 & - & 0,81 & - & - & - \\
\hline 890 & - & 0,77 & - & - & - \\
\hline 742 & - & 0,77 & - & - & - \\
\hline 946 & - & $-0,74$ & - & $-0,80$ & $-0,81$ \\
\hline 1708 & - & - & 0,84 & - & - \\
\hline 963 & - & - & 0,80 & $-0,84$ & $-0,85$ \\
\hline 1692 & - & - & 0,77 & - & - \\
\hline
\end{tabular}

Вместе с тем возможна интерпретация электронных спектров сложных соединений с отнесением полос к определенным электронно-колебательным переходам и получением необходимой информации. При этом наибольший интерес представляют $\pi \rightarrow \pi^{*}$ переходы в сопряженных молекулярных структурах, особенно ароматиче- ских молекул. Ароматические молекулы в соответствии с теорией Хюккеля имеют $(4 n+2)$ сопряженных р-электрона, характеризуются низким энергетическим уровнем и обладают четко выраженными полосами поглощения. Примерами таких молекул служат бензол $(n=1)$, нафталин $(n=2)$, антрацен $(n=3)$ и нафтацен $(n=4)$ (рис. 2) [5]. 
Применение ультрафиолетовой спектроскопии в сочетании с другими методами (ИК, КР, ЯМР и ЭПР) позволяет идентифицировать и определять структуры химических соединений, изучать равновесие и кинетику химических реакций и межмолекулярные взаимодействия в химмотологических системах.

Методы электронной ультрафиолетовой спектроскопии нашли свое применение для определения содержания в топливах ароматических, моно-, би- и полициклических углеводородов, антиокислительных присадок в топливах и синтетических маслах, альдегидов и кетонов в смолах, выделенных из дизельных топлив, а также для определения качества этиленгликоля (ГОСТ 19710-83), оценки солюбилизирующей способности дизельных топлив и т. д.

В отличие от молекулярной оптической спектроскопии, где имеется возможность исследования твердых, жидких и газообразных образцов, в атомно-абсорбционной спектроскопии (ААС) требуется перевод атомов исследуемого образца в газообразную фазу. Атомно-абсорбционная спектроскопия представляет быстрый, доступный и эффективный метод достаточной чувствительности, информативность которого возрастает в сочетании с масс-спектрометрическим анализом.

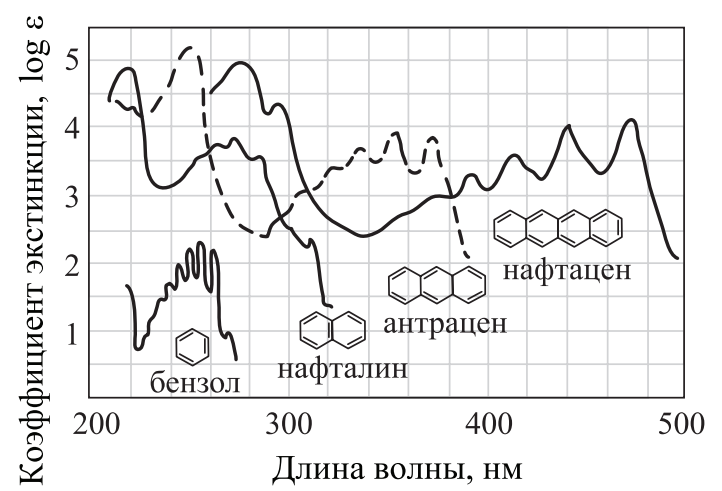

Рис. 2. Спектры поглощения ароматических углеводородов

Методы атомно-абсорбционной спектроскопии широко используются при количественном и качественном определении содержания металлов в дизельных и остаточных топливах, маслах, смазках и специальных жидкостях. Дополнением к атомноабсорбционной спектроскопии является атомно-эмиссионная спектроскопия (АЭС), эффективная для количественного многоэлементного спектрального анализа смазочных материалов, осадков, нагаров, лаков и отложений, а также оценки влияния состава коррозионной среды на скорость коррозии металлов. Пределы обнаружения ионов металлов, определяющих ключевую роль в химмотологических процессах методами атомноабсорбционной и атомно-эмиссионной спектроскопии, представлены в табл. 2.

Таблица 2

Пределы обнаружения ионов металлов методами атомно-абсорбционной спектроскопии и атомно-эмиссионной спектроскопии на приборах «Perkin Elmer Inc.» [5]

\begin{tabular}{|c|c|c|c|c|c|c|}
\hline \multirow[b]{2}{*}{ Элемент } & \multirow{2}{*}{$\begin{array}{c}\text { Смазочные } \\
\text { материалы, осадки, } \\
\text { нагары, лаки, отложения }\end{array}$} & \multirow[b]{2}{*}{ дт } & \multirow[b]{2}{*}{ OT } & \multicolumn{3}{|c|}{ Предел обнаружения, мкг/л } \\
\hline & & & & AАC (пламенный) & $\begin{array}{c}\text { ААС } \\
\text { (графитовый) }\end{array}$ & $\begin{array}{c}\text { АЭС } \\
\text { (плазма) }\end{array}$ \\
\hline $\mathrm{Al}$ & + & + & - & 45,0 & 0,005 & 0,6 \\
\hline $\mathrm{Ca}$ & + & - & - & 1,5 & 0,1 & 0,5 \\
\hline Co & + & + & - & 9,0 & 0,15 & 0,2 \\
\hline $\mathrm{Cr}$ & + & - & - & 3,0 & 0,004 & 0,2 \\
\hline $\mathrm{Cu}$ & + & + & - & 1,5 & 0,014 & 0,2 \\
\hline $\mathrm{Mg}$ & + & - & - & 0,15 & 0,004 & 0,04 \\
\hline Mo & + & + & - & 45,0 & 0,03 & 0,5 \\
\hline $\mathrm{Na}$ & + & + & + & 0,3 & 0,005 & 0,5 \\
\hline $\mathrm{Ni}$ & + & + & - & 6,0 & 0,07 & 0,5 \\
\hline $\mathrm{Pb}$ & + & - & - & 15,0 & 0,05 & 1,0 \\
\hline $\mathrm{Si}$ & + & - & - & 90,0 & 1,0 & 10,0 \\
\hline Sn & + & - & - & 150,0 & 0,1 & 2,0 \\
\hline $\mathrm{Ti}$ & + & - & - & 75,0 & 0,35 & 0,4 \\
\hline V & + & + & + & 60,0 & 0,1 & 0,5 \\
\hline W & + & - & - & 1500,0 & - & 1,0 \\
\hline $\mathrm{Zn}$ & + & - & - & 1,5 & 0,02 & 0,2 \\
\hline
\end{tabular}

Примечание: дт - дизельные топлива; ОТ — остаточные топлива. 
В настоящее время на базе методов спектроскопии разработаны методики контроля за наличием и содержанием присадок в автомобильных бензинах. Введение в действие технического регламента о требованиях к топливам исключило применение в составе автомобильных бензинов металлсодержащих присадок. Существующий фотоколориметрический метод не позволяет достоверно сделать вывод об отсутствии металлсодержащих присадок в бензине, что определило необходимость разработки методики на базе метода атомноадсорбционной спектроскопии, используемого при определении свинца и марганца в автомобильных бензинах $[7,8]$. Методика основана на определении содержания железа в бензине по поглощению его резонансной аналитической линии (248,3 нм) с помощью двухлучевого атомно-абсорбционного спектрометра AAnalist 200 фирмы PerkinElmer со спектральным диапазоном 190...900 нм, разрешением не менее 0,3 нм и погрешностью фотометрирования не более 0,5 \% [9].

Современный уровень компьютеризации и автоматизации спектроскопических методов обеспечил их использование не только при проведении уникальных химмотологических исследований, но и в области оценки соответствия нефтепродуктов требованиям нормативной документации и технических регламентов (табл. 3). При этом наибольшее распространение получили методы инфракрасной (определение оксигенатов и бензола), атомно-абсорбционной (определение марганца и свинца) и флуоресцентной спектроскопии (определение серы), включающей методы энергодисперсионной рентгенофлуоресцентной спектрометрии, ренгенофлуоресцентной спектрометрии с дисперсией по длине волны и ультрафиолетовой флуоресценции.

Таблица 3

Физические методы, применяемые для подтверждения соответствия продукции техническому регламенту*

\begin{tabular}{|c|c|c|}
\hline Продукция & Характеристика & Физический метод (национальный стандарт) \\
\hline \multirow{8}{*}{$\begin{array}{l}\text { Автомобильный } \\
\text { бензин }\end{array}$} & \multirow{3}{*}{ Массовая доля серы } & $\begin{array}{l}\text { Определение серы методом энергодисперсионной } \\
\text { рентгенофлуоресцентной спектрометрии (ГОСТ Р 51947-2002, } \\
\text { ЕН ИСО 20847-2010, ASTM D 4294-10) }\end{array}$ \\
\hline & & $\begin{array}{l}\text { Определение содержания серы рентгенофлуоресцентной } \\
\text { спектрометрией с дисперсией по длине волны (ГОСТ Р 52660-2006, } \\
\text { ЕН ИСО 20884-2004, ASTM D 7039-07) }\end{array}$ \\
\hline & & $\begin{array}{l}\text { Определение содержания серы методом ультрафиолетовой } \\
\text { флуоресценции (ГОСТ Р ЕН ИСО 20846-2006) } \\
\end{array}$ \\
\hline & $\begin{array}{l}\text { Объемная доля } \\
\text { бензола }\end{array}$ & $\begin{array}{l}\begin{array}{l}\text { Определение бензола методом инфракрасной спектроскопии } \\
\text { (ГОСТ Р 51930-2002) }\end{array} \\
\end{array}$ \\
\hline & $\begin{array}{c}\text { Концентрация } \\
\text { марганца }\end{array}$ & $\begin{array}{l}\text { Определение марганца методом атомно-абсорбционной } \\
\text { спектроскопии (ГОСТ Р 51925-2011) }\end{array}$ \\
\hline & \multirow{2}{*}{$\begin{array}{l}\text { Концентрация } \\
\text { свинца }\end{array}$} & $\begin{array}{l}\text { Определение свинца методом атомно-абсорбционной спектрометрии } \\
\text { (ГОСТ Р 51942-2010) }\end{array}$ \\
\hline & & $\begin{array}{l}\text { Определение малых концентраций свинца методом } \\
\text { атомно-абсорбционной спектрометрии (ГОСТ Р ЕН 237-2008) }\end{array}$ \\
\hline & $\begin{array}{l}\text { Объемная доля } \\
\text { оксигенатов }\end{array}$ & $\begin{array}{l}\text { Определение МТБЭ, ЭТБЭ, ТАМЭ, ДИПЭ, метанола, этанола } \\
\text { и трет-бутанола методом инфракрасной спектроскопии } \\
\text { (ГОСТ Р 52256-2004) }\end{array}$ \\
\hline \multirow{3}{*}{$\begin{array}{l}\text { Дизельное } \\
\text { топливо }\end{array}$} & \multirow{3}{*}{$\begin{array}{l}\text { Массовая } \\
\text { доля серы }\end{array}$} & $\begin{array}{l}\text { Определение серы методом энергодисперсионной } \\
\text { рентгенофлуоресцентной спектрометрии (ГОСТ Р 51947-2002) }\end{array}$ \\
\hline & & $\begin{array}{l}\text { Определение содержания серы рентгенофлуоресцентной } \\
\text { спектрометрией с дисперсией по длине волны } \\
\text { (ГОСТ Р 52660-2006, ЕН ИСО 20884-2004) }\end{array}$ \\
\hline & & $\begin{array}{l}\text { Определение содержания серы методом ультрафиолетовой } \\
\text { флуоресценции (ГОСТ Р ЕН ИСО 20846-2006) } \\
\end{array}$ \\
\hline Топочный мазут & Массовая доля серы & \multirow{4}{*}{$\begin{array}{l}\text { Определение серы методом энергодисперсионной } \\
\text { рентгенофлуоресцентной спектрометрии (ГОСТ Р 51947-2002) }\end{array}$} \\
\hline $\begin{array}{l}\text { Топлива для } \\
\text { реактивных } \\
\text { двигателей }\end{array}$ & \multirow{2}{*}{$\begin{array}{c}\text { Массовая доля } \\
\text { общей серы }\end{array}$} & \\
\hline $\begin{array}{l}\text { Авиационный } \\
\text { бензин }\end{array}$ & & \\
\hline Судовые топлива & Массовая доля серы & \\
\hline
\end{tabular}

*Технический регламент «О требованиях к автомобильному и авиационному бензину, дизельному и судовому топливу, топливу для реактивных двигателей и топочному мазуту» (постановление Правительства РФ от 27.02.2008 г. № 118). 
Флуоресцентная спектроскопия основана на анализе характеристического спектра флуоресцентного излучения пробы, которое возникает под действием рентгеновского или ультрафиолетового излучения. Спектральный анализ этого излучения адекватно отражает элементный состав анализируемого вещества, а интенсивность характеристических линий - количественное содержание.

Несмотря на то что в основе работы современных спектроскопических методов лежат принципы и законы, сформулированные более ста лет назад, их совершенствование не прекращается: повышаются

\section{СПИСОК ЛИТЕРАТУРЫ}

1. Пентин Ю. А., Вилков Л. В. Физические методы исследования в химии. - М. : ООО «Издательство АСТ», 2003. - 683 с.

2. Брандт Дж., Энглинтон Г. Применение спектроскопии в органической химии / Пер. с англ.; Под ред. Ю. Н. Шейнкера. — М. : Мир, 1967. — 279 с.

3. Моющие присадки к автомобильным бензинам и их количественное определение / В. А. Винокуров [и др.] // Мир нефтепродуктов. — 2010. — № 3. - С. 21-26.

4. Чечкенев И. В. Разработка новых методов химмотологических исследований // Труды 25 ГосНИИ МО РФ. - 1988. - Вып. 51. - С. 147-151.

5. Шмидт В. Оптическая спектроскопия для химиков и биологов. - М. : Техносфера, 2007. -368 c.

6. ГОСТ Р 52530-2006. Бензины автомобильные. Фотоколориметрический метод определения железа. — Введ. 2007-01-01. — М. : Стандартинформ, 2007.

7. ГОСТ Р 51925-2011. Бензины. Определение марганца методом атомно-адсорбционной спектроскопии. — Введ. 2013-07-01. — М. : Изд-во стандартов, 2012. — 8 с.

8. ГОСТ Р 51942-2012. Бензины. Определение свинца методом атомно-адсорбционной спектрометрии. - Введ. 2012-07-01. - М. : Изд-во стандартов, 2002. - 12 с.

9. Приваленко А. Н., Балак Г. М., Пуляев Н. Н. Разработка метода определения концентрации железа в автомобильном бензине с использованием атомно-абсорбционной спектрометрии // Международный научный журнал. — 2011. — № 5. — С. 119-123.

\section{REFERENCES}

1. Pentin Yu. A., Vilkov L. V. Fizicheskie metody issledovaniya v khimii. — M. : OOO «Izdatel'stvo AST», 2003. - 683 p.

2. Brandt Dzh., Englinton G. Primenenie spektroskopii v organicheskoy khimii / Per. s angl.; Pod red. Yu. N. Sheynkera. - M. : Mir, 1967. - 279 p.

3. Moyushchie prisadki $\mathrm{k}$ avtomobil'nym benzinam i ikh kolichestvennoe opredelenie / V. A. Vinokurov [etc.] // Mir nefteproduktov. — 2010. — № 3. — pp. 21-26.

4. Chechkenev I. V. Razrabotka novykh metodov khimmotologicheskikh issledovaniy // Trudy 25 GosNII MO RF. - 1988. — Vyp. 51. - pp. 147-151.

5. Shmidt V. Opticheskaya spektroskopiya dlya khimikov i biologov. — M. : Tekhnosfera, 2007. — $368 \mathrm{p}$.

6. GOST R 52530-2006. Benziny avtomobil'nye. Fotokolorimetricheskiy metod opredeleniya zheleza. — Vved. 2007-01-01. — M. : Standartinform, 2007.

7. GOST R 51925-2011. Benziny. Opredelenie margantsa metodom atomno-adsorbtsionnoy spektroskopii. — Vved. 2013-07-01. — M. : Izd-vo standartov, 2012. — 8 p. 
8. GOST R 51942-2012. Benziny. Opredelenie svintsa metodom atomno-adsorbtsionnoy spektrometrii. — Vved. 2012-07-01. — M. : Izd-vo standartov, 2002. - 12 p.

9. Privalenko A. N., Balak G. M., Pulyaev N. N. Razrabotka metoda opredeleniya kontsentratsii zheleza $\mathrm{v}$ avtomobil'nom benzine $\mathrm{s}$ ispol'zovaniem atomno-absorbtsionnoy spektrometrii // Mezhdunarodnyy nauchnyy zhurnal. — 2011. — № 5. — pp. 119-123.

Материал поступил в редакцию 18.06.13.

Орешенков Александр Владимирович, доктор техн. наук

Тел. (499) 149-64-81

Приваленко Алексей Николаевич, канд. техн. наук, доцент

Тел. 8 (499) 141-97-37, 8-916-386-44-19

Балак Галина Михайловна, канд. хим. наук, стариий научный сотрудник

Пуляев Николай Николаевич, канд. техн. наук, доцент

Тел. 8 (499) 976-09-57

E-mail: toplivo@msau.ru 